\title{
Integrating Learning ObJectives in a Multi-Semester Sustainable Conservation Design Project for First-Year Students During a Pandemic
}

\author{
Libby Osgood and Nadja Bressan \\ Faculty of Sustainable Design Engineering \\ University of Prince Edward Island \\ eosgood@upei.ca,nbressan@upei.ca
}

\begin{abstract}
Project selection for first-year design courses can be complicated by the limited skill level of students in their first semester of an engineering program and the scalability required for multiple sections and large classes. Additionally, the project must address the course's learning objectives and provide a sense of authenticity to help students understand the role of engineers in society. A first-year design course can be seen by students as the 'introduction to engineering,' enabling them to decide whether to pursue engineering as a profession or not.

In addition to the already taxing demands imposed on a project for a first-year design course, students at the University of Prince Edward Island completed a design project encompassing two engineering courses and contributed to a scientific research study on bat conservation. Partnering with researchers in the Atlantic Veterinary College, students designed, built, and installed bat houses equipped with sensors to remotely collect temperature, humidity, and the presence of individual bats within the colony. Constructing 21 bat houses promoted conservation efforts of bats across the province and taught students the critical role of engineers in a sustainable society.

This paper presents a discussion on project selection for first-year design courses, how the learning objectives were met for two first-year design courses during a pandemic, and describe the community partner's role throughout the design project.
\end{abstract}

Keywords: Sustainability, Bat conservation, Engineering education, First-year design, Community partners

\section{INTRODUCTION}

There has been an increased interest in bats following the recent Covid-19 outbreak in Wuhan, China. The discovery that these Wuhan bats can coexist with and transmit the virus whilst displaying no symptoms has raised questions about bats in Canada [1]. Meanwhile,
Canada is home to seventeen bat species, with the most common of those being the Little Brown Bat, with three of those being present in Prince Edward Island, including the most recent finding of the eastern red bat (Lasiurus borealis), during the Fall of 2020 [2,3].

Some of the indicators of Covid-19 in humans are respiratory issues and increased temperature; however, Little Brown bats that harbor the viruses (through natural or experimental infection) display no overt signs of having the disease [4,5]. The hibernating bats discovered with the disease exhibited normal hibernation temperatures of 3$6^{\circ} \mathrm{C}$ and normal torpor heart rates of 6-32 bpm [6,7]. While the Little Brown Bat is resting, its heart rate is between 210-457 bpm, and while in flight, the heart rate goes up to 1368 bpm [7]. A bat's normal (non-hibernation) temperature is $36^{\circ} \mathrm{C}[6]$.

Bats have a fundamental role in our ecosystem that impacts agriculture and forestry activities. By eating insects, the propagation of diseases is prevented. Through pollination, a wild variety of plants are produced for medicine and consumption. Engineering developed several modern technologies mimicking the bat' organism, such as low temperature surgeries, military sonar, blood-clot medications, etc. However, a few questions about their behavior and organism are still unanswered, such as the influence of climate change and the mobility of bat's colonies or the lack of population data to determine patterns and accurate status of their conservation status.

For first-year students in a sustainable design engineering program, bat conservation and monitoring is an ideal first design project. The ability to build and instrument bat houses requires an appropriate level of complexity for (i) construction of the bat houses, (ii) electronics knowledge to instrument the bat houses, and (iii) method of data analysis to interpret results. Additionally, the project is authenticated as a real-world problem, helping students understand an engineer's role in society. 
This paper will address how the learning objectives were met for two first-year design courses, describe the community partner's role throughout the design project, and include a discussion on project selection for a first-year design course. Additional attention will be given to how this was accomplished while adhering to pandemic protocols.

\section{Project Constraints}

\subsection{Curricular Landscape}

At University of Prince Edward Island (UPEI), Sustainable Design Engineering students take eight semesters of design throughout their degree. The industrybased design projects increase in complexity corresponding to the students' technical abilities and experience at each year of study. In the first year, the design courses are focused on Engineering Communication in the first semester and Engineering Analysis in the second semester. The design projects are Community Design projects where the partners are from community-based organizations, incorporating elements of service-learning projects. Past partners include Mikinduri Children of Hope [8], PEI Farm Centre [9], and Parks Canada [10].

In the fall of 2020, students in the first semester Engineering Communications design course worked with three clients: (i) bat population researchers to design and build bat houses, (ii) AbleGamers Charity [11] to solve a specific problem to make gaming more accessible for people with disabilities, and (iii) Parks Canada to research and propose creative solutions to several problems experienced at the Prince Edward Island National Park. Through these projects, students developed their technical communication skills. They learned to sketch and use CAD software to express their designs digitally. They wrote technical reports and presented their ideas to the client in formal technical presentations. They learned the importance of accurate drawing packages by constructing one of their designs: bat houses. Finally, they used team communication software and completed personal reflections and group evaluations to develop their teamwork and interpersonal skills.

In the winter of 2021, students in the second semester Engineering Analysis design course continued two of the projects from the first semester. For Parks Canada, students iterated their initial design ideas incorporating feedback from the client. Students performed analyses on their specific problem, built and tested a prototype, and presented the results to the client. Through the bat project, students explored basic circuit design using Arduinos and sensors. They practiced experiment design, data collection, cleaning, and analysis, then interpreted and presented the results. Through the use of a real project using real data, students experienced all stages in data analysis, from

CEEA-ACEG21; Paper 084

University of Prince Edward Island; June 21 - 23, 2021-2 of 7 - collecting the data to preprocessing and graphically presenting the results.

\subsection{Discussion on Project Selection}

Students arrive at university from varied backgrounds with different experiences and abilities. Their writing, math, and science skills vary based on the courses they took in high school. Their familiarity with tools is widely varied [12]. Some students come to university with construction experience, and some students have never held a hammer. Students come with different understandings of teamwork and different levels of communication skills [13]. A first-year design project should be selected to welcome all levels of ability and experience. The project should challenge students but not be so daunting that students disengage. There should be an element of creativity to prevent the regurgitation of identical projects and to allow students to express themselves and explore different possibilities.

First-year design courses can be considered an introduction to the practice of design. Students in their first semester evaluate whether they want to pursue engineering or switch to a different major before too much time has passed [12]. As a result, projects for first-year design courses must provide a sense of realism, representing some aspect of the engineering profession [14].

This authenticity can be provided through hypothetical design projects, where the user or client is not involved, but there is an authentic problem to solve. These afford students a sense of realism and help them understand the impact of engineering on society, one of the graduate attributes required of the Canadian Engineering Accreditation Board (CEAB). Online project banks provide descriptions of real projects that require solutions [15-17].

Providing students with a real client who is experiencing the problem allows students to practice empathy [18]. Students are more engaged and determined to find an optimal solution. Specifically women and people from underrepresented groups engage when the client is a community partner as in service-learning projects $[19,20]$.

It is not uncommon to have the end-user represented by an intermediary organization that advocates on their behalf. For example, the bats were unable to speak for themselves in this project, so the bat researchers articulated the problem for them. While the students considered the researchers to be the client, the bat houses were designed for the bats, and the sensor housings on the bat houses were tailored to the needs of the researchers. These complexities can create opportunities for conversations to clarify the intent of the project with the students and to emphasize the role of the end-user or client. When paired with reflection, these conversations can enhance the development of their understanding of the impact of engineering on society [21].

Intermediary individuals or organizations may be required when the end-user is geographically distant or has 
limited connectivity. This is common in global projects where the intermediary may have traveled regularly to the location and communicates regularly with the end-users. A meaningful experience can exist by having an intermediary as the client, but there is the potential that the intermediary client provides inaccurate information, oversimplifies the problem, or 'others' the end-user, isolating the client from the students and the intermediary. If possible and appropriate, providing an interaction with the end-user (in some form) can produce more accurate information, whether through written communication or arranging a special Q\&A. This is not always possible and sometimes not advisable, depending on the needs of the end-user.

When defining the activities involved in a project, considerations must be made concerning the needs of the client. Often, it is not possible to connect a client with every section of a first-year design course, especially for multiple or large sections. This would demand a lot of time and patience for the client to explain the same text multiple times. However, in this digital age, a meaningful connection can be forged between the client and students. Similar to a flipped classroom, the presentation of the problem can be recorded, students can prepare questions, and the client can be available for each section (or smaller group of students) for a Q\&A session. The saves the client from explaining the same content repeatedly and allows the students to rewatch the video as needed. This is especially helpful for students who do not speak English as their first language.

An additional consideration for project selection is the scope of the project and expected deliverables. Are students expected to produce hand sketches, CAD design, physical prototypes, or a combination? Is there an expectation for design reports or formal presentations? The amount of time devoted to the project will determine the scope of the project.

If teams are employed, class time should be made available for teams to connect. The understanding of expected participation when working in teams varies significantly, especially for first-year students. Some students genuinely do not understand that they are expected to attend all team meetings and contribute to the design. Providing class time helps integrate less responsive students into the team.

Many aspects of the project selection have been presented in this section, though this discussion is not intended to be comprehensive. A project should be challenging, engaging, provide an element of creativity, and pose a real problem, ideally with a real client. The scope and expected deliverables should match the abilities of the students with consideration for the length of the project [22]. A potential client needs to be aware of these potential limitations and set reasonable expectations based on the abilities of first-year students. When expectations are realistic and appropriate constraints are in place for a project, it is possible for both students and clients to feel a positive outcome has been achieved.

\subsection{Impact of Bat Behavior on Project}

For this project on bat behavior, an ideal timeline that to meet course learning objectives would have students:

(i) fabricate bat houses and communicate the design in the fall,

(ii) construct the circuits and instrument the bat houses in January,

(iii) collect data in February, and

(iv) analyze data in March.

Unfortunately, bats do not follow the academic calendar. Most Canadian bat species mate in the fall, then the females store the sperm in their uterus for the duration of winter hibernation [2]. Once they leave hibernation in spring, the females ovulate and fertilize the egg, giving birth 60 days after conception, usually in mid-June [2]. Bat females live in maternity colonies during the summer. [2]. These colonies can have up to 1000 bats in them [23].

The ideal time to collect data on bat habitation on PEI is June through September, the months when the students are not enrolled in design. Thus, the course's learning objectives were modified to pilot data collection techniques by allowing students to design their own data collection experiments to learn about the overall process of data analysis. In the summer, after both design courses are complete and when the bats are not hibernating, the bat houses will be instrumented, and data collection for research purposes will begin. It would be better if the students' data actually contribute to the research project, but concessions must be made to adhere to the academic timeline.

A second impact on the project due to bat behavior was the selection of sensors for instrumentation. Bats echolocation ranges in frequency between approximately $11 \mathrm{kHz}-212 \mathrm{kHz}$. [24]. Most bats who prey on insects use $20 \mathrm{kHz}-60 \mathrm{kHz}$, as any lower and the wavelengths would be lower than the insect wing length, making echoes weaker [24]. Canadian bats are insectivores, with most bats consuming close to $50 \%$ of their body weight and pregnant females eating more than $100 \%$ of their body weight nightly [2]. An ultrasonic microphone was required to measure echolocation in the target frequency range. A dual-purpose temperature and humidity sensor was required to determine the ideal comfort level for bats, and an IR sensor was required to determine whether bats were present in the house.

For a class of 75 students, it would be cost-prohibitive to purchase all of the necessary sensors for each student. One solution could be to have students share equipment and have access to all of the sensors, but because the learning objective is focused on data collection, a more meaningful learning experience would result from fewer sensors with individual kits than sharing kits with more sensors. Additionally, the ultrasonic microphone 
necessitates a more complex data analysis than is required to meet the course learning objectives. Therefore, due to cost and complexity, the students used humidity, temperature, and infrared sensors to learn about data analysis.

\subsection{Impacts of COVID-19}

An acknowledgment must be made of the effect that COVID-19 had on this project. In one sense, COVID-19 was a motivating factor to learn more about bat habitats and habits, to possibly uncover why bats who have COVID-19 do not exhibit symptoms. Each university responded differently to the pandemic. As PEI is an island, the provincial government has greater control over access points.

UPEI required mandatory quarantine efforts, increased cleaning requirements, social distancing measures, and the use of masks. With these restrictions, engineering students took classes using a hybrid model, where classes were primarily online with an in-person element at the discretion of the instructor.

Design courses consisted of one online class where break-out rooms allowed for groupwork and one in-person class where groups could interact six feet apart and wearing masks. This took much more space and required extra break-out rooms so teams could disperse to allow team members to speak louder across the six-foot distances and through masks.

An additional impact was to the build schedule. Usually, a project would have the prototype built towards the end of the semester, after students: (i) completed safety training, (ii) learned how to use CAD software, (iii) produced a drawing package, and (iv) worked with a few different teams. With the potential risk of shut-down due to COVID-19 outbreaks, the build had to occur much earlier, as early as possible, which compressed the schedule and learning objectives into a three-week period during the first semester. The students reported that the busy pace heightened the level of excitement. Because the students had no previous experience with design courses, they were not as impacted by the compressed schedule as expected.

Once building began, it became clear that social distancing wasn't possible at all times. Students continued to wear masks and found ways to keep their safety glasses from the fogging effect caused by the masks. The social distancing requirement was relaxed in cases where students had to help each other hold the device or manipulate material during the construction phase.

During the second semester, students returning from winter break who left PEI were required to quarantine. This delayed the start of the electronics assembly by two weeks to ensure all students could attend in person in the same hybrid model as the first semester. Flexibility and responsiveness are necessities for design courses, especially during a global pandemic.

\section{PROJECT IMPLEMENTATION}

In this section, the timeline, learning objectives, and role of the client will be interwoven into a chronological project description. There were two sections of students with similar enrollment numbers in both the fall and winter semesters. There were 45 students in one section and 30 students in the other section, with no discernable differences between the two sections. Table 1 shows the course objectives, client objectives, and complicating factors encountered during the project.

Table 1: Objectives. Select Engineering Communications Course Objectives

- Produce technical documents to describe the work performed in the design process to technical and non-technical audiences.

- Produce clear diagrams and engineering sketches using traditional and electronic methods

- Build self-confidence and earn the trust and confidence of colleagues through competent and timely task completion

- Explain the roles and responsibilities of the professional engineer in society

- Understand how sustainability affects engineering design during and beyond the design process.

Engineering Analysis Course Objectives

- Identify the characteristics of datasets

- Identify corrupted data from usable data

- Structure and cleaning data

- Design data processing to understand, interpret, and drive conclusions

- $\quad$ Present Data Graphically and Numerically

- Examining Relationships: utilizing Quantitative Data

- Design effective data visualizations

Client Objectives

- $\quad$ Promote bat conservation

- $\quad$ Provide bat houses to members of the public

- Produce sample bat houses to use as exemplars at public events

- Increase awareness of bat conservation in students and the general population

- Gather data on bat habits and habitats

Complicating Factors

- Bat behavior

- COVID-19 social distancing during the build

- $\quad$ Risk of potential shut down

\subsection{Pre-Course Planning}

Two different instructors taught the two engineering courses. This required coordination of the two projects shared across the two courses (bats and Parks Canada), while ensuring the learning objectives are all satisfied for both courses. Regardless of the particular project, the learning objectives must be met. It is the responsibility of 
the instructor to ensure that the project offers opportunities to meet the specific learning goals while also meeting the expressed needs of the client, despite the complicating factors.

The two instructors, a lab technician responsible for the build, and the clients met in the summer to scope the project. The clients expressed a desire to have model bat houses to use as exemplars for public information sessions. They also requested that the houses that would not have sensors be given to the public to promote bat conservation. Both objectives were added to the overall list of project objectives.

\subsection{First Semester Bat House Build}

In the first full week of the fall semester class, the students were introduced to the project during an online class. The following problem statement was posed to the students:

This project aims to design, build and deploy bat houses with sensors to measure temperature, humidity, sound, and heart rate. The information collected will serve to better understand the impact of the environment on the animals. We hypothesize that temperature and humidity are decisive factors when bats chose the location of their roost.

Students were asked to consider the placement of the sensors to ensure the bats would not be disturbed when the researcher access the electronics. Students were provided a set of requirements and an instructional manual on the management of bats on PEI [23]. Teams were formed and spent the remaining class time preparing questions to ask the client during the following class.

There were two client representatives, and each representative spoke with one of the two sections of students for about 90 minutes. The clients gave background information on bat behavior and habits and answered many questions from the students. The clients intentionally did not show pictures of bat houses so that students would perform the research on types of houses and have room for creativity.

That weekend, students submitted individual CAD models of their proposed designs to facilitate finalizing the team's design. The following week, the teams made rough drawings of their proposed designs on paper, and once those were approved by the lab technician and instructor, the students began building their prototype. The provided materials were sheets of plywood, chipboard, scrap $2 \times 4$ 's, metal hinges, and fasteners. Students were given additional access to the lab throughout the week, and by Friday, only $2 \frac{1}{2}$ weeks from the beginning of the semester, there were 21 constructed bat houses. That weekend, students submitted CAD assemblies of their completed bat houses, drawing packages, and design reports documenting the design decisions. The following week, students completed a structured reflection on their performance, evaluating their CAD skills, documentation skills, communication with teammates, and professionalism. This first part of the project was completed in an incredibly compressed schedule, which was necessitated by the risk of a COVID shut down.

The client was on-site during the build process to give advice and provide feedback on the designs. Four of the bat houses were selected for instrumentation. Two bat houses were used by the researchers for public events. The remaining 15 bat houses were given to the public to promote bat conservation. Figure 1 shows the creativity of one of the teams with the incorporation of the 'Batman' design on the bat house. Another team turned the house itself into the shape of a bat.

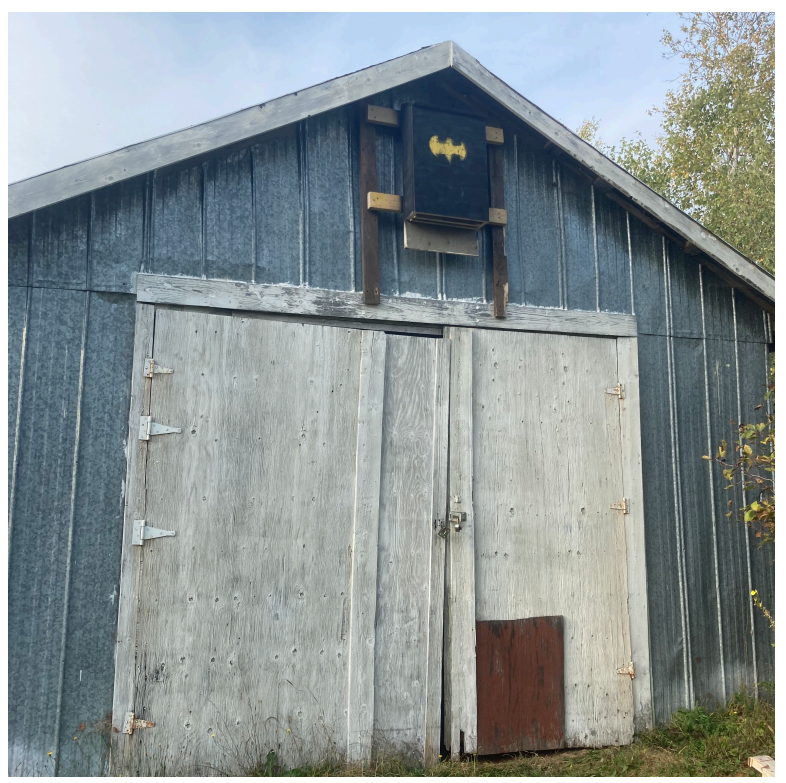

Fig. 1. Installed bat house.

One complication that arose during the build was that the sensor housing was not accessible enough once the bat house was installed. The students failed to consider the wall behind the bat house given the hinge placement and range of motion of the sensor housing door. Several teams had to adapt their design to position the presence sensor in a more appropriate location close to the opening. Additionally, very few of the teams considered how to install the bat house and had to retroactively add flanges for mounting. The course instructor and lab technician intentionally did not suggest that students consider installation early in the design process, to see whether teams would incorporate this without prompting. Though it would be dramatic to call these necessary adaptations 'failures', learning through failure affords a learning experience that is more impactful than if the students were told to incorporate these details ahead of time.

All of the first-semester learning objectives identified in Table 1 were addressed in this portion of the project. The objectives map to five different CEAB graduate attributes: (i) design, (ii) use of engineering tools, (iii) communication 
skills, (iv) professionalism, and (v) impact of engineering on society and the environment.

\subsection{Second Semester Data Collection \& Analysis}

Following a more relaxed schedule without the fear of shut down, the project was resumed during the third week of the second semester. The delay of two weeks ensured that students who traveled off-Island during the winter break were out of quarantine and able to participate in person. Winter storms further impacted the schedule for section 2, with a week delay on coding and deploying the circuits.

For the second semester of the bat project, students were introduced to breadboards and electronics. The materials for each person a breadboard, Arduino-nano, temperature and humidity sensor, infrared sensor, battery connector, and wires. They were provided with the programming code and corresponding schematic to build the circuit. Students devised experiments, such as collecting temperature and humidity data from the shower or counting the number of people that pass through the doorways. The creativity in experiment design was an unintended benefit from not being able to collect data using the bat houses. Students then submitted the collected data, and the following two classes were devoted to clean, prepare, and process the data. They learned statistical techniques and submitted analysis reports.

The students performed a reflection activity on the challenges they encountered during the data collection and analysis process. Based on what they learned about battery life and the sensors, the students submitted recommendations to improve and optimize the data collection for the bat houses. These suggestions were provided to the client.

All course learning objectives presented in Table 1 were addressed for this project. These objectives map to the following CEAB graduate attributes: (i) problem analysis, (ii) design, (iii) use of engineering tools, and (iv) professionalism.

\subsection{Client Objectives}

Of the five objectives, the client's main desire was to promote bat conservation, and 21 bat houses were constructed. Two of the bat houses were hand-picked by the client to be used as exemplars at public events, fulfilling an objective. The four bat houses that had the best design for the sensor housing were installed for data collection, which is set to begin in the summer of 2021. The remaining 15 bat houses were made available to the public and installed across Prince Edward Island during the fall, which satisfied an additional objective. The final objective to increase awareness of bat conservation in students and the public was met through a news story broadcast on CBC about the students and their design projects. In addition, the story instilled a sense of pride in the students and helped them to see how an engineer (or engineering student) can impact society.

\section{CONCLusion}

This paper discussed the intricacies in selecting a project for a first-year design course and presented a case study for how the learning objectives were met for a project that spanned two semesters and supported academic researchers during a pandemic. All course objectives were met through the two semesters, and four of the five client objectives were met, with the fifth objective expected to begin this summer. The students built sturdy, creative bat houses and gained valuable communication and analysis skills.

Successful delivery of design projects requires a comprehensive plan and flexible implementation, as complications cannot be avoided. It is necessary to have an honest discussion with the client on the anticipated outcomes and realistic abilities of the students given the time constraint and materials. A well-framed project can ensure both students and clients have a positive experience and course learning objectives are met.

\section{References}

[1] Yi Fan, Kai Zhao, Zheng-Li Shi, and Peng Zhou, "Bat coronaviruses in China," Viruses, vol. 11, no. 3, pp. 210, March 2019. DOI: 10.3390/v11030210

[2] M. Brock Fenton, "Bat," The Canadian Encyclopedia, 25 March 2015, Historica Canada. Available as of Feb 18, 2021 from

https://www.thecanadianencyclopedia.ca/en/article/bat

[3] Atlantic Veterinary College. New Bat Species Recorded on PEI. Available as of Feb 20, 2021 from https://www.upei.ca/communications/news/2020/11/newbat-species-recorded-prince-edward-island

[4] Wei-jie Guan, Zheng-yi Ni, Yu Hu, Wen-hua Liang, et al., "Clinical characteristics of coronavirus disease 2019 in China," New England Journal of Medicine, vol. 382, no. 18, pp 1708-1720, 2020. DOI: 10.1056/NEJMoa2002032

[5] Arinjay Banerjee, Sonu Subudhi, Noreen Rapin, Jocelyne Lew, et al., "Selection of viral variants during persistent infection of insectivorous bat cells with Middle east respiratory syndrome coronavirus," Scientific Reports, vol. 10 , no. 1 , pp. 1-14, 2020. https://doi.org/10.1038/s41598020-64264-1

[6] Bats A Conservation Guide, Toronto Zoo, pp. 10-13. Available as of Feb 18, 2021 from http://www.torontozoo.com/!/pdfs/BatsConservationGuide.pdf

[7] R. Mark Brigham, David Ianuzzo, N Hamilton, and M B Fenton, "Histochemical and biochemical plasticity of muscle fibers in the little brown bat (Myotis lucifugus)," Journal of Comparative Physiology B, vol. 160, no. 2, pp. 183-186, 1990. 
[8] Mikinduri Children of Hope. Available as of Feb 18, 2021 https://mikinduri.com/

[9] PEI Farm Centre. Available as of Feb 18, 2021 www.peifarmcentre.com

[10] Parks Canada. Available as of Feb 18, 2021 www.pc.gc.ca

[11] AbleGamers Charity. Available as of Feb 18, 2021 ablegamers.org

[12] Aezeden Mohamed, "First year engineering, hands-on, team design project course: Reflections of a Ph.D. student/teaching assistant," Education Practice and Innovation, vol. 2, no. 3, pp. 1-8, 2015. https://doi.org/10.15764/EPI.2015.03001

[13] David W. Johnson and Roger T. Johnson, Cooperation and competition: Theory and research. Interaction Book Company, 1989, 265 pp. \{ISBN-13: 978-0939603107\}

[14] Marco Antonio Carvalho Pereira, Maria Auxiliadora Motta Barreto, and Marina Pazeti, "Application of project-based learning in the first year of an Industrial Engineering program: Lessons learned and challenges," Production, vol. 27, June 01, 2017. https://doi.org/10.1590/01036513.223816

[15] Ennomotive: Innovative Challenges solved through crowd sourcing. Available as of Feb 18, 2021 https://www.ennomotive.com/innovation-challengescrowdsourcing/

[16] Innocentive. Available as of Feb 18, 2021 https://www.innocentive.com/

[17] Engineering 4 Change. Available as of Feb 18, 2021 www.engineeringforchange.org

[18] Jihane Kojmane and Ahmed Aboutajeddine, "Strengthening engineering design skills of first-year university students under resources constraints," International Journal of Mechanical Engineering Education, vol. 44, no. 2, pp. 148-164, 2016. https://doi.org/10.1177/0306419016641006

[19] Marybeth Lima, "Service-learning: A unique perspective on engineering education," in Projects that matter: Concepts and models for service-learning in engineering, E. Tsang (ed), AAHE's Seies on Service-Learning in the Disciplines, AAHE Press, pp. 109-118, 2000.

[20] Linda Barrington and John J. Duffy, "Attracting underrepresented groups to engineering with servicelearning," Proceedings of the 2007 American Society of Engineering Education International Exposition and Conference. ASEE, June 2007. DOI: 10.18260/1-2--2993

[21] Annie Pearce and William Manion, "Service learning for sustainability: A tale of two projects," Procedia Engineering, vol. 145, pp. 50-57, 2016. https://doi.org/10.1016/j.proeng.2016.04.013

[22] R. Casey Cline, Ken Robson, and Michael Kroth, "Construction management service learning: A "How To" process for success," International Journal for Service Learning in Engineering, Humanitarian Engineering and Social Entrepreneurship, vol. 9, no. 2, pp. 85-92, 2014. DOI: $10.24908 / \mathrm{ijsle.v9i2.5451}$

[23] Tessa McBurney, Got Bats? A guide for conservation minded bat exclusion in Prince Edward Island, Oct 2018. Available as of Feb 18, 20201 http://www.cwhc-rcsf.ca

[24] Gareth Jones, and Marc W. Holderied. "Bat echolocation calls: Adaptation and convergent evolution," Proceedings of the Royal Society B: Biological Sciences, vol. 274, no. 1612, pp. 905-912, 2007.

https://doi.org/10.1098/rspb.2006.0200 